\title{
Lipid profile in type $r$ diabetic patients in Mosul
}

\author{
Samir B. Al-Mukhtar \\ Department of Biochemistry, Nineveh College of Medicine, \\ University of Mosul
}

Received: $1 \mathrm{r} / 9 / \mathrm{r} \ldots 0$; Accepted: $r / 1 \cdot / \mathrm{r} \ldots \mathrm{O}$

Objectives: (a)To examine the effects of diabetes and its duration on lipid profile. (b)To

determine the prevalence of dyslipidaemia on lipid profile.

Design: Case-control study.

Setting: The study was conducted in Al-Zahrawi private Hospital in Mosul from January to December $r^{\prime}$. 纟.

Participants: Three hundred and fifty six type $r$ diabetic patients who attended outpatient department and $r \wedge \varepsilon$ apparently healthy controls.

Main outcome measures: Plasma glucose and serum lipid profile in type $r$ diabetic patients were compared with controls. The collected data were analyzed by chi-square, Z, one-way ANOVA and Duncan tests.

Results: Serum total cholesterol (TC), low density lipoprotein cholesterol (LDL-C), very low density lipoprotein cholesterol (VLDL-C) and serum triglycerides (TG) were increased significantly $(\mathrm{P}<\bullet . \cdot)$; however, high density lipoprotein cholesterol (HDLC) was decreased significantly $(\mathrm{P}<\bullet . \cdots)$ in diabetic patients as compared with controls. No significant difference was noticed between males and females for lipid profile. The lipid profile was increased with advancement of disease. There was a significant difference between patients in fasting plasma glucose and fasting serum lipid concentrations according to advancement of disease in duration. The prevalence of hypercholesterolaemia, hypertriglyceridaemia, hyper LDL cholesterolaemia and low HDL cholestrolaemia among the studied patients according to the recommendation of British Hyperlipidaemia Association (1991) was $79.7 \%, r 7.4 \%, \uparrow \wedge . \wedge \%$ and $7 \leqslant \%$ respectively. Duration of disease was associated with higher incidence of dyslipidaemia. Conclusion: Diabetes mellitus is associated with lipid abnormalities. Periodic check up of lipid profile is recommended for diabetic patients. There is positive relationship between duration of diabetes and lipid profile.

Key words: Lipid profile, Diabetes type r, Dyslipidaemia, Lipoproteins.

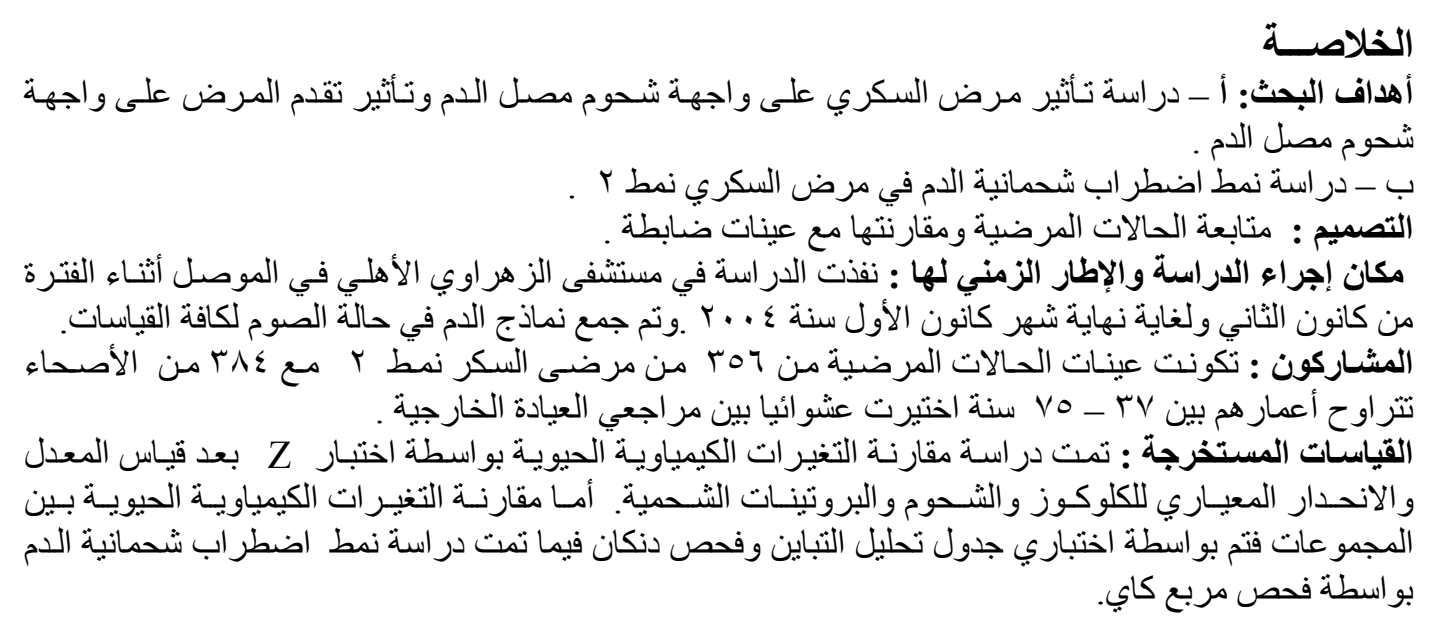




\section{Introduction}

S everal risk factors for coronary heart disease (CHD) have been reported including diabetes mellitus, obesity, hypertension and dyslipidaemia $^{(}, r^{r}$. Diabetes mellitus is regarded as a major independent risk factor responsible for hyperlipidaemia and CHD development ${ }^{(r, i)}$. Furthermore, dyslipidaemia has been shown to be the main contributor to the increased incidence of coronary events and death among diabetic subjects $\left.{ }^{(}\right)$. Accordingly, management of type $r$ diabetes is essential by the control of hyperglycaemia and dyslipidaemia $^{(r)}$. In addition to that, much attention is focused to improve disordered lipoprotein metabolism, the changes observed were not only an elevated serum concentration of total cholesterol (TC) and triglycerides (TG) but also on altered composition and protein moieties of lipoproteins ${ }^{\left.(\urcorner,{ }^{\vee}\right)}$.

This study was done to examine the effects of diabetes and its duration on lipid profile. In addition, to determine the prevalence of dyslipidaemia in type

$r$ diabetic patients in Mosul.

\section{Subjects and Methods}

The study ran from January to December $Y . . \varepsilon$. It was performed on patients diagnosed as diabetic and their fasting glucose was not less than $v$. $\mathrm{mmol} / \mathrm{L}^{(\wedge)}$. Patients with any other diseases except type $r$ diabetes were excluded from this study. Three hundred and fifty six diabetic patients were included in this study attending Al-Zahrawi Private Hospital outpatient department. Patients ( $\mid \wedge \leqslant$ males, IVY females) aged $r V_{-} V_{0}$ years (mean $\pm \mathrm{SD}$, or.0 \pm 7. ). All patients were under treatment of sulfonylureas tablets in addition to diet restriction. Those patients were divided into three groups according to the duration of diabetes. Group I having diabetes for $<0$ years ( $V \circ$ males, $V \leqslant$ females), group II having diabetes from $\left.\tau_{-}\right)$- years ( $7 \tau$ males, $7 \leqslant$ females), group III having diabetes $>1$. years ( $\leqslant r$ males, $r \leqslant$ females). The control group included $r \wedge \varepsilon$ apparently healthy subjects ( $\wedge$ r males, $Y \cdot r$ females) aged $r \Lambda_{-} \vee r$ years (mean $\pm \mathrm{SD}$, $\left.\varepsilon \wedge \cdot+ \pm^{\top} \cdot 0\right)$.

Blood sample $(\mathcal{l} \cdot \mathrm{ml})$ was taken from each subjects after an overnight fasting and divided into two aliquots. The first aliquot was transferred into fluorideoxalate tube for plasma glucose measurement and the other aliquot was transferred into plain tube for serum lipid profile. Determination of serum total cholesterol (TC), triglycerides (TG) and high density lipoprotein cholesterol (HDL-C) was performed by using enzymatic method ${ }^{(9)}$. Low density lipoprotein cholesterol (LDL-C) was determined using Friedewald formula 
for those with triglycerides <£.0 $\mathrm{mmol} / \mathrm{L}^{(\cdot)}$. LDL-cholesterol $(\mathrm{mmol} / \mathrm{l})=$ Total cholesterol - HDL-cholesterol - triglycerides $\mathrm{x} \cdot . \leqslant 00$

VLDL-cholesterol was calculated from the formula: VLDL-C $(\mathrm{mmol} / \mathrm{l})=$ Triglycerides $\mathrm{x} \cdot . \leqslant 00^{(\cdot)}$.

Classification of hyperlipidaemia and dyslipidaemia was based on the recommendation of the British Hyperlipidaemia Association $(199 \wedge)^{(1)}$ using thresholds of triglycerides $>1 \wedge$. $\mathrm{mg} / \mathrm{dl}(r . \varepsilon \mathrm{mmol} / \mathrm{L})$, total cholesterol $>19 \leqslant \mathrm{mg} / \mathrm{dl}(0 \cdot \mathrm{mmol} / \mathrm{L})$, LDL-C $>$ $117 \mathrm{mg} / \mathrm{dl}(\Gamma \cdot \mathrm{mmol} / \mathrm{L}), \mathrm{HDL}-\mathrm{C}<\varepsilon 0$ $\mathrm{mg} / \mathrm{dl}(1.10 \mathrm{mmol} / \mathrm{L})$, total cholesterol: HDL-C $>0 . \cdot$, LDL-C:HDL-C $>r . \bullet$, and triglycerides: HDL-C $>r . \cdot$ A subject was considered dyslipidaemic when one of the above criteria was fulfilled $^{(1)}$. Data was represented as mean $\pm \mathrm{SD}$. Unpaired $\mathrm{Z}$ test was used to determine the difference between the means. Analysis of variance (ANOVA) and Duncan tests were used to compare the biochemical changes among the groups and within the groups. Chisquare test used for comparison of percentage. P-value at $<\cdot .0$ was considered as significant.

\section{Results}

Table I showing that plasma glucose in the diabetic patients was significantly higher than in the control group $(\mathrm{P}<\cdot, \cdots)$. $\quad$ Furthermore, total cholesterol, LDL-C, VLDL-C and TG were highly significant than those measurements in the control group $(\mathrm{P}<\cdot . \cdot 1)$, at the same time HDL-C was significantly lower than that in the control group $(\mathrm{P}<\bullet . \cdots)$. In addition, there was no significant difference between males and females for plasma glucose and lipid profile (data is not shown).

According to the duration of diabetes an upward trend was observed in the mean plasma glucose and all serum levels of TC, LDL-C, VLDL-C and TG with advancement of the disease $(\mathrm{P}<\cdot . \cdot 1)$ while there was a decline in HDL-C with advancement of the disease i.e. lower in group III than in group I and II. According to the duration of diabetes on plasma glucose and lipid profile a significant decrease was present within groups $(\mathrm{P}<\cdot . \bullet)$ (I, II and III) in the levels of fasting plasma glucose, TC and LDL-C, also there was significant increase between groups I and II, and groups I and III in the levels of VLDL-C and TG while there was a significant decrease between the same groups in the levels of HDL-C (Table

A subject was considered dyslipidaemic when the criteria of cutoff value was fulfilled according to the recommendation of British hyperlipidaemia Association (Recommendation of Coronary Prevention 1991). The prevalence of hypercholesterolaemia, hypertriglyceridaemia, hyper LDL cholesterolaemia and low HDL cholesterolaemia among the type $r$ diabetes was $79.7 \%, \uparrow 7 . \curlyvee \%, 7 \wedge . \wedge \%$ and $\tau \leqslant \%$ respectively. An abnormal ratio of certain lipoprotein components was also noticed in the studied patients as such ratio has been recommended to use for assessment by British Hyperlipidaemia Association ( $199 \wedge$ ). However, or. $\wedge \%$ of patients had TC: HDL-C >0.', $\vee ฯ . \wedge \%$ had LDL-C: HDL-C $>$ r.0 and $I V .1 \%$ had TG/HDL-C $>r$. ( (Table $r$ ). Comparison of percentage in the male and female groups using chi-square revealed statistically significant difference only in the LDL-C: HDL-C ratio $(\mathrm{P}<\cdot .0)$. 
Table ( '): Plasma glucose and serum levels of lipid profile in the control subjects and diabetic patients represented as mean $\pm S D$.

\begin{tabular}{|c|c|c|c|}
\hline Parameters $\mathrm{mmol} / \mathrm{L}$ & Control subjects $(n=\Gamma \wedge \Sigma)$ & Diabetic patients $(n=r \circ\rceil)$ & P-value \\
\hline Glucose & $0.11 \pm \cdot . V Y$ & $1 \cdot .7 \wedge \pm r .01$ & $\mathrm{p}<\underset{1}{ }$ \\
\hline Total cholesterol & $\varepsilon .9 \cdot \pm \cdot . \wedge \Lambda$ & $0.7 \varepsilon \pm 1 . v$ & $\begin{array}{c}\mathrm{p}< \\
1\end{array}$ \\
\hline HDL-C & $1.17 \pm .1 \%$ & $I \cdot \pm \cdot r \cdot$ & $\mathrm{p}<\ldots$ \\
\hline LDL-C & $r .99 \pm \cdot .11$ & $r .21 \pm 1.1$. & $\mathrm{p}<\cdots$ \\
\hline VLDL-C & $\cdot r \cdot \pm \cdot . I V$ & $. \Sigma 1 \pm \cdot$. YO $^{\prime}$ & $\begin{array}{c}\mathrm{p}< \\
1\end{array}$ \\
\hline Triglycerides & $1.7 \cdot \pm \cdot \wedge \varepsilon$ & $r .1 T \pm 1 . r V$ & $\mathrm{p}<\cdots$ \\
\hline
\end{tabular}

Table ( $($ ): Plasma glucose and serum lipid profile in diabetic patients according to the duration of disease represented as mean $\pm S D$.

\begin{tabular}{|c|c|c|c|c|}
\hline $\begin{array}{c}\text { Parameters } \\
\mathrm{mmol} / \mathrm{L}\end{array}$ & $\begin{array}{l}\text { Group I } \\
<0 \text { years } \\
(n=1 \leq 9)\end{array}$ & $\begin{array}{l}\text { Group II } \\
\left.\tau_{-}\right) \cdot \text { years } \\
\left(n=1 \Gamma^{\prime} \cdot\right)\end{array}$ & $\begin{array}{c}\text { Group III } \\
>1 \cdot \text { years } \\
(n=V \vee)\end{array}$ & ANOVA \\
\hline Glucose & $\begin{array}{c}1.70 \pm 1.99 \\
a\end{array}$ & $1 \cdot .9 r \pm r .1 r$ & $|\varepsilon . r| \pm r .0 r$ & $\begin{array}{l}\mathrm{p}<\cdots \cdots 1 \\
\mathrm{~F}=\text { or. } \varepsilon\end{array}$ \\
\hline Total cholesterol & 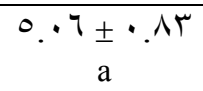 & $0 . \leqslant V_{\frac{1}{b}} \cdot .97$ & 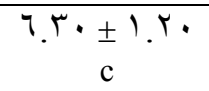 & $\begin{array}{l}\mathrm{p}<\cdots \cdots 1 \\
\mathrm{~F}=\mathrm{ry}_{\mathrm{q}} \varepsilon\end{array}$ \\
\hline HDL-C & $1.1 T \pm \frac{ \pm}{a}$ & $\begin{array}{c}.0 \pm \\
b\end{array}$ & $1 \cdot r \pm \frac{r}{b} \cdot r \leqslant$ & $\begin{array}{l}\mathrm{p}=. .19 \\
\mathrm{~F}=\varepsilon .\end{array}$ \\
\hline LDL-C & $r_{\mathrm{a}} \cdot \Lambda_{ \pm} \cdot \lambda V$ & $r_{\mathrm{b}} \mu_{ \pm} \cdot .9 \wedge$ & $\varepsilon .11 \pm 1.1 \varepsilon$ & 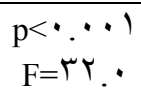 \\
\hline VLDL-C & $. r_{a} \pm .19$ & $\because \varepsilon \varepsilon \pm \frac{b q}{b}$ & $\because \leqslant \frac{T^{\prime}}{b} \cdot r V$ & $\begin{array}{c}\mathrm{p}<\cdots \cdots \\
\mathrm{F}=7 .\end{array}$ \\
\hline Triglycerides & $\begin{array}{c}1.10 \pm .90 \\
a\end{array}$ & $r^{r} \prod_{b}+1 . \leqslant 0$ & $r . r \leq \frac{ \pm}{b} . \leq \varepsilon$ & $\begin{array}{c}\mathrm{p}=\bullet \cdots \mathrm{r} \\
\mathrm{F}=\mathrm{r} .\end{array}$ \\
\hline
\end{tabular}

Different letters horizontally mean a significant difference at $\mathrm{p}<\cdot . \cdot \bullet$ level according to

Duncan test.

Table ( $\left.{ }^{\boldsymbol{}}\right)$ : Prevalence of dyslipidaemia in the diabetic patients according to the recommendation of the British Hyperlipidaemia Association. Results are expressed as number (\%) of patients with gender prevalence.

\begin{tabular}{|c|c|c|c|c|c|c|c|c|c|c|c|c|c|c|}
\hline \multirow[t]{2}{*}{ Sex } & \multicolumn{2}{|c|}{$\begin{array}{c}\text { TG } \\
\geq r . \varepsilon \\
\mathrm{mmol} / \mathrm{L}\end{array}$} & \multicolumn{2}{|c|}{$\begin{array}{c}\text { TC } \\
\geq 0 . \\
\mathrm{mmol} / \mathrm{L}\end{array}$} & \multicolumn{2}{|c|}{$\begin{array}{l}\text { LDL-C } \\
\geq{ }^{\circ} \cdot \\
\mathrm{mmol} / \mathrm{L}\end{array}$} & \multicolumn{2}{|c|}{$\begin{array}{l}\text { HDL-C } \\
\leq 1.10\end{array}$} & \multicolumn{2}{|c|}{$\begin{array}{c}\text { TC:HDL- } \\
\text { C } \\
\geq 0\end{array}$} & \multicolumn{2}{|c|}{$\begin{array}{c}\text { LDL-C:HDL-C } \\
\geq r .0^{\circ}\end{array}$} & \multicolumn{2}{|c|}{$\begin{array}{c}\text { TG: HDL-C } \\
\geq \Gamma\end{array}$} \\
\hline & No. & $\%$ & No. & $\%$ & No. & $\%$ & No. & $\%$ & No. & $\%$ & No. & $\%$ & No. & $\%$ \\
\hline Males & $0 \wedge$ & 17.4 & $\begin{array}{l}11 \\
0\end{array}$ & ro. & IT & T.V & 110 & "ז.Tr & 97 & r..9 & Trו & rV.o & YV & V.7 \\
\hline Females & VI & 19.9 & 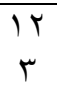 & $r \leqslant .0$ & $\begin{array}{l}1 T \\
0\end{array}$ & ro. & 111 & I.V & 97 & r.. & $1 \leq$. & rq.r & TE & 9.0 \\
\hline Both & 149 & r.Y & $\begin{array}{l}Y \leq \\
\wedge\end{array}$ & 79.7 & $\begin{array}{l}Y \leq \\
0\end{array}$ & $7 \wedge . \wedge$ & rrA & $7 \varepsilon$ & $\begin{array}{c}19 \\
r\end{array}$ & or.A & rVT & $\vee T . \wedge$ & 71 & $1 V .1$ \\
\hline P-value & & IS & & vS & & $\mathrm{VS}$ & & & & $\mathrm{NS}$ & $\because$ & (S) & & $\mathrm{NS}$ \\
\hline
\end{tabular}

\section{Discussion}


In the present study (TC) was increased significantly in diabetic patients. This result was consistent with other studies $^{(1 r-10)}$. Abate et al. (1990) found that TC and LDL-C were increased in diabetes especially with advanced age $^{(\urcorner)}$. The major cause of increased atherogenic risk is hypercholesterolaemia, and both genetic disorders and diets enriched in saturated fat and cholesterol contributes to the elevated lipid levels characteristics of patients with premature CHD. There is now

High serum LDL-C was noted to be significantly increased with duration of the disease. This is in agreement with the findings of other studies ${ }^{(1 \varepsilon}, r^{\prime}, r^{\prime)}$. The fact that diabetes causes an increase in serum concentration of small, dense LDL molecules $\left.{ }^{(r,}{ }^{r(}\right)$, which easily undergo oxidation and speedup progression of atheromatous plaque ${ }^{(\mathrm{V})}$. Serum triglycerides (TG) and VLDL$\mathrm{C}$ are increased in diabetic patients which is obvious in the present study, and their levels were significantly increased with the duration of disease, which are consistent with other studies $^{\left(r \varepsilon, r^{\circ}\right)}$, while are inconsistent with other studies ${ }^{\left(r Y,{ }^{r v}\right)}$. This variation could be due to difference in geographical, cultural $^{(\Upsilon Y)}$ economical, social conditions $^{\left({ }^{\wedge} \wedge\right)}$, dietary habits and genetic makeup $^{(\Upsilon q)}$. Moderately elevated levels of triglycerides are often associated with metabolic syndrome or syndrome $\mathrm{X}^{(\tau \cdot)}$. Furthermore, the poorly controlled situation offers abundant substrates, including glucose, fatty acids and triglycerides ${ }^{(r)}$. High triglycerides and low HDL-C are reported as important and independent risk factors for $\mathrm{CHD}^{(r r)}$.

There is a close relationship between triglycerides and small, dense LDL particles $^{\left({ }^{(T)}\right.}$ which are thought to be more atherogenic than native LDL-C $\mathrm{C}^{(r \varepsilon)}$. Triglycerides are also associated with increased levels of plasminogen activator inhibitor-1 which is also universal acceptance of cholesterol diet CHD hypothesis ${ }^{(17)}$.

It is well known fact that low HDL-C

is common in type $r$ diabetes and may be a strong risk factor for $\mathrm{CHD}^{(1 Y, 1 \wedge)}$. Which is consistent with the present study results that low HDL-C is evident compared with the control group. Framingham study suggested that TC: HDL-C ratio is a useful summary of the joint contribution of TC and HDL-C to $\mathrm{CHD}^{(19)}$.

widely considered to be cardiovascular risk factor ${ }^{(\Gamma 0)}$.

In the present study the prevalence of hypercholesterolaemia, hypertriglyceridaemia, hyper LDL-cholesterolaemia and low HDL cholesterolaemia among type $r$ diabetes according to the recommendation of British Hyperlipidaemia Association (199^), ${ }^{(1)}$ was $79.7 \%, \quad r 4 . \Upsilon \%, \quad 71 . \wedge \%$ and $\quad 7 \leqslant \%$ respectively. These results are consisted with several other studies ${ }^{\left(r \longleftarrow,{ }^{r v}\right)}$. Data from National Health And Nutrition Examination Survey (NHANES) study indicate that $v . \%$ of diabetic patients have high or borderline high cholesterol $^{\left({ }^{\wedge}\right)}$. Never the less, the prevalence of hyper-triglyceridaemia in the present study falls in the range of $r \cdot-7 . \%$ as reported in other study ${ }^{(r q)}$. The prevalence of low HDL-C levels in the present work was consistent with other studies $\left.{ }^{(r \longleftarrow,}{ }^{r \vee}\right)$. The possible explanation of dyslipidaemia which is double than normal in type $r$ diabetes is due to the fact that fat cells release large amount of free fatty acids to the circulation, which are taken up by the liver, then lipoprotein synthesis is enhanced followed by assembly and secretion of increased amount of VLDL-C $\mathrm{C}^{(1)}$.

In conclusion based on these findings subject with lipid abnormalities and higher plasma glucose should be early detected and carefully managed to prevent CHD because diabetes is usually regarded as major risk for CHD 
and all diabetics should be educated about dyslipidaemia and their serum lipid levels should be checked regularly.

\section{References}

1. Kannel WB. A general cardiovascular risk profile. The Framingham study.

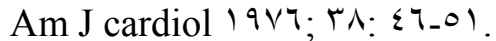

$r$. Ferando DJS, Sinibadda SH, Desilva $\mathrm{DR}$, perera SD. The prevalence of obesity and other coronary risk factors in suburban Srilanka community. Asia Pacific J Clin Nutr $199 \leqslant ;$; $100 \_109$. r. Dunn FL. Hyperlipidemia in diabetes mellitus. Diabetes Metab Rev 199.;

$$
\text { ๆ: }\left\{V_{-} \top\right\} \text {. }
$$

£. El-Hazmi MAF, Warsy AS, AlSwailem AR, Al-Swailem AM, Sulaiman R, Al-Meshari AA. Diabetes mellitus and impaired glucose tolerance in Saudi Arabia. Ann Saudi Med 1997; 17: rN1_rNo. -. Joslin PEP. Arteriosclerosis and diabetes. Ann chim med. I9VT; O: $1.71-1 . v 9$.

ฯ. Abate N, Vega GL, Garg A, Grundy SM . Abnormal cholesterol distribution among lipoprotein fractions in normolipidemic patients with mild NIDDM. Atheroselerosis 1990; 111: 111-1 Kr.

$\checkmark$. Lyons TJ. Oxidized LDL: Arole in the pathogenesis of atherosclerosis in diabetes. Diabetic Med 1991; ^: $\leqslant 11-$ «19.

$\wedge$. Report of the Expert committee on the diagnosis and classification of diabetes mellitus. Diabetic Care 199v; $r \cdot(v)$ : 11Ar-119V.

9. Stein EA ,Myers GL. Lipids, Apolipoprotiens \& Lipoprotiens . In: Burtis CA, Ashwood ER,Aldrich JE. Teitz Fundamentals and Clinical Chemistry, $\varepsilon^{\text {th }}$ ed. Philadelphia, WB

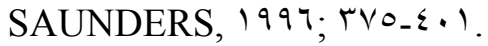
1. Friedewald WT, Levey RI, Fredrickson DS. Estimation of the concentration of low-density lipoprotein cholesterol in plasma without use of ultracentrifuge. Clin Chem 19VY; 1 1.: $\leqslant$ 9_00Y.
1). Wood D, Durrington P, poulter N: Joint British recommendations on the prevention of coronary heart disease in clinical practice. Heart 1991; $\wedge$. (Suppl. r): $1-r q$. 1r. Mohamad M, Arshad F, Mohd Noor I, Ali R. Prevalence of dyslipidaemia in non-insulin-dependent diabetic patients attending armed forces clinics in kuala Lumpur. Asia Pacific J Clin Nutr 199V; $r(r): r \cdot r-r \cdot \tau$. 1r. Vajifdar BU, Goyal VS, Lokhandwala YY, Mhamun Kar SR, Mahadik SP, Gawad AR et al. Anthropometry, lipid profile and dietary pattern of patients with chronic ishaemic heart disease. Journal of Postgraduate Medicine 1999, $\leqslant 0(\xi)$ : $11 \cdot-114$.

I ₹. Simonen PP, Gylling H, Miettnen TA. Body weight modulates cholesterol metabolism in non-insulin dependant type $r$ diabetes. Obesity Research r..r; 1.: rrs. rro. 10. Sindelka G, Skrha J, Prazny M, Hass T. Association of obesity, diabetes, Serum lipids and blood pressure regulates insulin action. Physiol $r \ldots r$; 10_91.

17. Thompson GR, Barter PJ. Clinical lipidology at the end of the millennium. Curr Opin Lipidol. 1999; 1.: or 1_ort.

IV. Laakso M. Dyslipidemia, morbidity and mortality in non-insulin dependent diabetes mellitus. J Diabetes Complications 199v; $\left.11(r): \mid r v_{-}\right) \leq 1$. \^. Betteridge DJ. Diabetic Dyslipidemia. Am J Med 199 ; 97 ( 7 ): Suppl ro_rl. 19. Castelli WP, Garrison RJ, Wilson PWF, Abbot RD, Kalousdian S, Kannel WB. Incidence of coronary heart disease and lipoprotein cholesterol levels. The Framingham study. J Am Med Assoc 1910; ror:

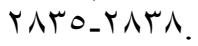
$r \cdot$. Laws A, Marcus BB, Grave JS, Curb JD. Lipid and lipoprotein as a risk factor for coronary heart disease in men with abnormal glucose tolerance. J Intern Med I $99 \%$ r $r \leqslant(0): \leqslant V$ _ $\leqslant \vee \wedge$. 
५. . Luzniak P, Czech A, Taton J, Luzniak $\mathrm{AW}$. Ischemic heart disease in patients with non-insulin dependant diabetes mellitus. Polish Heart Journal $r \ldots r$; 07: 0...0.V.

$r$. Betteridge DJ. LDL heterogeneity: Implications for atherogenicity in insulin resistance and NIDDM.

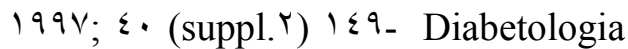
101.

rr. Syvanne M, Taskinen MR. Lipids and lipoproteins as coronary risk factors in non-insulin dependant diabetes mellitus. Lancet 199v; ro. (Suppl.'). IY.-IYT. $r \varepsilon$. Naheed T, Khan A, Masood G, Bin Yonus B, Chaudry MA. Dyslipidemias in type II diabetes mellitus patients in teaching hospital of Lahore, Pakistan.

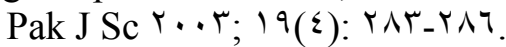
ro. El-Hazmi MAF, Al-Swailem AR, Warsy AS, Al-Meshari AA, Sulaimani R, Al-Swailem AM. Lipids and related parameters in Saudi type II diabetes mellitus patients. Ann Saudi

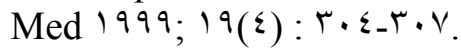
rч. Ronnemaa T, Laakso M, Kallio V. Serum lipids, lipoproteins and apolipoproteins at the excessive heart disease in non-insulin dependent diabetic patients. Am J Epidemiol $1919 ; 1 \% \cdot(\varepsilon): 7 r r-7 \leqslant 0$. rv. Hart C, Ecob R, Smith GD. People, places and coronary heart disease risk factors: a multilevel analysis of the Scottish heart health study archive. Soc Sc Med 199v; $\leqslant 0: \wedge 9 r-9 . r$. Y^. Vartiainen E, Pekkanen J, Koskinen S, Jousilahti P, Salomma V, Puskap. Do change in cardio vascular risk factors explain the increasing socioeconomic difference in mortality from ischemic heart disease in Finland? J Epidemiol Community Health 1911; or: ₹17_s19. rq. Shahid A, Zubri SJ, Hasnan N. Lipid pattern in healthy subjects. Pak Med Res 1910; rะ: rT_rV. $r$. National Cholesterol Education Program Expert Panel. Executive summary of third report of the national cholesterol education program (NCEP) expert panel on detection. Evaluation and treatment of high blood cholesterol in adult. (Adult treatment panel 111). J Am Med Assoc r... ; r ro: r $\leqslant \wedge r_{-} r \leqslant 9$. r. Stout RW. Macroangiopathy . Med

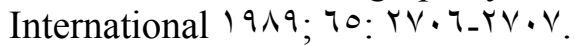
rr. Jeppesen J, Madsbad S. High triglyceride, Low HDL: Cholesterol and risk of coronary heart disease. Ugeskr laeger 1997; 101 ( 0 \%): 7197 . 19.1. (Abstract). rT. Haffner SM, Mykkenen L, Valdez RA, Paidi M, Stern M, Howard BV. LDL-size and subclass pattern in biethnic population. Arterioscler Thromb 199r; 1r: 17rr_l7r. $r \varepsilon$. Austin MA, Breslow JL, Hennekens $\mathrm{CH}$, Buring JE, Willett WC, Krauss RM. Low density lipoprotein subclass pattern and risk of myocardial infarction. JAMA 19^^; Yr.: 191V-19Y1.

ro. Stern M. Natural history of macrovascular disease in type $r$ diabetes. Diabetes Care 1999; YY(T): $1-\Lambda$.

ч. Wilson PWF, Kannel WB, Aderson KM. Lipids, glucose in tolerance and vascular disease: The Framingham study, Monoger Atheroscler 1910; 1r: 1- 11 .

rv. Haffner SM, sterm MP, Hazuda HP, Mitchell BD, Patterson JK. Cardiovascular risk factors in confirmed prediabetic individuals. Does the clock for coronary heart disease start ticking before the onset of clinical diabetes? JAMA 199.;

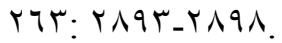

ץ^. Harris M. Hypercholesterolemia in diabetes and glucose intolerance in the US population. Diabetes Care

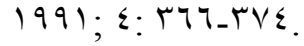
rq. Taskinen M., Quantitative and Qualitative lipoprotein abnormalities in diabetes mellitus. Diabetes 1994 ; \&) (Suppl. r) I Y IV. 
